\title{
Efeitos das Competências no Desempenho de Contratos de Serviços no Setor Público
}

Effects of Capabilities on the Performance of Public Sector Service Contracts 


\title{
Resumo
}

Com o intuito de contribuir para a literatura de Estratégia aplicada à Gestão Pública e auxiliar na tomada de decisão dos gestores públicos, o presente trabalho investigou os efeitos de competências públicas e privadas no custo e na qualidade de contratos de terceirização de serviços no setor público. Para tanto, foram estudados 167 contratos de serviços entre uma entidade da Administração Pública Federal e diversos provedores, privados entre 2002 a 2015. Os dados coletados foram organizados em uma base específica e analisados por meio de regressões multivariadas. Os resultados sugerem que, diante de um ambiente caracterizado por incentivos limitados e por um baixo nível de competição entre as empresas, a remuneração, a formação e a experiência dos agentes públicos possuem efeitos nulos ou contraditórios no desempenho dos contratos, particularmente nos indicadores de custo. Quanto às competências privadas, verificou-se que a experiência das empresas influencia positivamente nos indicadores de qualidade, porém, sob a ótica do interesse público, as capacidades financeiras - em particular, a liquidez geral afetam negativamente os indicadores de custo. Os resultados contribuem para avanços na discussão sobre as heterogeneidades presentes em relações cliente-fornecedor em contratos públicos e em seus efeitos sobre o desempenho.

Palavras-chave: competências públicas; competências privadas; contratos de serviços; terceirização; desempenho.

\begin{abstract}
With the intent of contributing to the Applied Strategy literature in Public Management and assisting public manager decision-making, this research investigated the effects of public and private capabilities on cost and quality of outsourced public sector service contracts. To do so, we studied 167 service contracts between a Federal Public Administration entity and various private providers, during the period from 2002 to 2015. Data collected were organized in a specific dataset and analyzed using multivariate regressions. Results suggest that, in the face of an environment characterized by modest incentives and a low level of competition between companies, public agent wages, training and experience have contradictory effects, or no effects at all, on contract performance, particularly for cost indicators. With respect to private capabilities, this study verified that company experience has a positive influence on quality indicators; however, from the public interest point of view, financial capacities - in particular general liquidity - negatively affect cost indicators. These results contribute advances in the discussion about the heterogeneities present in buyer-supplier relations in public contracts and their effects on performance.
\end{abstract}

Key words: public capabilities; private capabilities; service contracts; outsourcing; performance.

JEL Classification Codes: H83, P47, R5. 


\section{Introdução}

A partir da década de 1980, diversos governos do mundo, como Reino Unido, Estados Unidos, entre outros, terceirizaram parte de suas funções. As pesquisas recentes de Cabral, Lazzarini e Azevedo (2013) e Ménard (2012), bem como o estudo de Rangan, Samii e Van Wassenhove (2006), mostram que, na terceirização, a interação entre os setores público e privado se expressa, mediante um continuum com diferentes níveis de intensidade, abrangendo desde a privatização total e as parcerias públicoprivadas até sistemas de governança nos quais o governo retém o controle dos ativos e terceiriza a operação interna, a exemplo de consórcios, concessões ou contratação de empresas prestadoras de serviços.

A delegação de serviços públicos, por meio de terceirização, apresenta limitações, quais sejam: a incompletude contratual, ou seja, a incapacidade de o contrato definir todas as contingências que irão se manifestar na fase de execução (Williamson, 2005); a rigidez dos procedimentos burocráticos (Cabral, 2017; Girth, 2012); a dificuldade de medir o desempenho dos serviços contratados, em termos tanto de custo quanto de qualidade (Boyne, 2002); o dilema custo-qualidade, ou seja, a tendência de as empresas reduzirem custos em detrimento da qualidade (Hart, Shleifer, \& Vishny, 1997); e os incentivos limitados (Dixit, 2002).

No contexto descrito anteriormente, os gestores públicos precisam delegar para organizações externas atividades antes realizadas pela sua própria estrutura (Pereira, 1997) e administrar as relações com as firmas antes e depois da celebração do contrato (Brown \& Potoski, 2003). Por sua vez, as empresas privadas necessitam desenvolver capacidades para compreender as demandas das entidades públicas e conviver com as restrições burocráticas existentes (Cabral, 2017). Diante desse ambiente, por um lado, surge para os gestores públicos, por um lado, o desafio de superar as limitações apontadas, conciliar objetivos conflitantes e criar valor nas relações público-privadas (Mahoney, McGahan, \& Pitelis, 2009). Por outro, há a necessidade de que novos estudos aprofundem questões relativas aos fatores que influenciam no desempenho dos contratos de serviços, às circunstâncias pelas quais as estratégias escolhidas encontram mais chances de sucesso, à integração de competências heterogêneas e complementares de agentes públicos e privados, e à criação de valor para a sociedade (Cabral et al., 2013; Mahoney et al., 2009; Rangan, Samii, \& Van Wassenhove, 2006).

Não obstante a existência dos estudos recentes já apontados, pouco se sabe sobre em que medida dimensões e componentes das competências organizacionais e individuais influenciam no desempenho dos contratos de terceirização de serviços. Percebe-se, então, a necessidade de novos trabalhos que forneçam contribuições teóricas para uma maior compreensão do papel das competências nas compras públicas - especialmente no âmbito da aquisição de serviços - e que permitam o aprofundamento de novas perspectivas da Gestão Estratégica no campo da Administração Pública. Referimo-nos, portanto, à necessidade de uma análise dos fundamentos das competências organizacionais e individuais e de suas relações com o desempenho organizacional, na linha de estudos recentes na área de estratégia (Felin, Foss, Heimeriks, \& Madsen, 2012). A partir do contexto assim delineado, apresenta-se a seguinte questão de pesquisa: Em que medida competências públicas e privadas podem influenciar o desempenho de contratos de terceirização de serviços no âmbito da Administração Pública?

Para responder à questão apontada anteriormente e atingir o objetivo deste trabalho ${ }^{(1)}$, foram analisados os efeitos das competências públicas e privadas nas dimensões custo e qualidade de contratos de terceirização de serviços. O trabalho empreendido reveste-se de pioneirismo ao desagregar os componentes de competências (capabilities) no setor público brasileiro e pretende compreender melhor a dinâmica de relações cliente-fornecedor em contexto relevante, porém pouco explorado: o das organizações públicas. Como unidade de análise, foram adotados os contratos dos serviços de recepção, portaria, vigilância, limpeza, transporte e manutenção celebrados pela Universidade Federal da Bahia (UFBA), no período de 2002 a 2015. A escolha da referida universidade para a realização da pesquisa se justifica pelo fato de essa instituição estar sujeita à mesma legislação que rege as demais entidades federais brasileiras. Além disso, a UFBA, como outras entidades públicas brasileiras, apresenta 
contratos que abrangem tipos heterogêneos de serviços, favorecendo o exercício de comparações na análise e na interpretação dos dados. Os serviços mencionados, prestados de forma contínua, beneficiam uma ampla comunidade de usuários, totalizando - entre alunos, docentes, funcionários técnicoadministrativos e prestadores de serviços - 39.282 pessoas (UFBA, 2016) e consomem $41 \%$ do orçamento anual com despesas de funcionamento, equivalendo, em média, a R \$ 57 milhões (UFBA, 2015). Pelos motivos indicados, o conjunto dos contratos estudados constitui uma amostra bem representativa de organizações públicas.

Além desta introdução, o estudo está organizado em mais quatro seções. Na segunda seção, é exposto o marco teórico de suporte e são colocadas as hipóteses de pesquisa. Na terceira, são descritos os procedimentos metodológicos utilizados na investigação empírica. A quarta seção trata sobre a apresentação e a discussão dos resultados. A quinta e última seção, enfim, apresenta a conclusão, além das implicações e das limitações do trabalho.

\section{Teoria e Hipóteses}

O problema de delegação de atividades para terceiros é estudado pelas teorias contratuais da firma, entre as quais se destaca a teoria dos contratos incompletos (Hart et al., 1997). De acordo com essa abordagem, alguns requisitos do produto/serviço não são contratáveis, pois não é possível especificá-los antes da celebração do contrato (ex ante) de forma a prever todas as possíveis ocorrências que surgirão depois (ex post). Devido a essas lacunas, a empresa contratada, cuja remuneração é fixa, seria incentivada para reduzir custos em detrimento da qualidade ou, pelo menos, negligenciar as melhorias qualitativas de produto/serviço ou processo. Trata-se do famoso dilema custo-qualidade.

A fim de proporcionar maior compreensão dos fenômenos envolvidos, estudiosos, a partir do final dos anos 1990, têm procurado incorporar à análise de contratos a abordagem das competências ou das capacidades (na literatura científica internacional, sob o termo de capabilities approach), fundamentada na obra seminal de Barney (1991). Esse autor introduz a Visão Baseada em Recursos (RBV), uma teoria transversal entre a Economia das Organizações e a Estratégia, que analisa a relação entre as características intrínsecas de uma organização e seu desempenho. De acordo com Barney (1991), a vantagem competitiva de uma organização pode se tornar estrategicamente sustentável unicamente quando baseada em recursos heterogêneos e intransferíveis (isto é, recursos específicos que não podem ser adquiridos no mercado), que sejam valiosos, únicos, raros, imperfeitamente imitáveis e que não possam ser substituídos por ativos estrategicamente equivalentes. Esses recursos - em particular, as pessoas, as experiências, os conhecimentos, as relações, os sistemas de controle e coordenação, e a forma peculiar de amalgamar esses atributos entre si - assumem um papel central para o desenvolvimento de uma organização no longo prazo (Barney, 1991).

A partir de pesquisas recentes, Andrews, Beynon e McDermott (2015), Cabral (2017) e Ménard (2012), além do estudo de Rangan et al. (2006), entende-se que, para serviços que preveem a proximidade de agentes públicos e privados, a interação entre organizações de natureza diferente dotadas de recursos complementares - permite geração de sinergias, integração dinâmica de processos, implementação de inovações, adoção de práticas comuns e aprendizagem recíproca, superando, assim, as limitações apontadas pelas teorias contratuais. Quando agentes públicos e privados se juntam na realização de um serviço público graças ao estabelecimento de relações próximas e à repetição frequente de operações, pode criar-se uma integração de competências heterogêneas e complementares (Cabral et al., 2013; Mahoney et al., 2009; Rangan et al., 2006). Portanto, capacidades públicas e privadas podem facilitar o alinhamento dos respectivos interesses, propiciar a superação da incompletude contratual e produzir resultados que agreguem valor para a coletividade no longo prazo (Cabral, 2017). No caso de contratos de serviços, a presença de agentes públicos - especializados no monitoramento - e de agentes privados - envolvidos na execução - permite obter complementariedade de papéis entre agentesfiscalizadores e agentes-executores (Cabral \& Lazzarini, 2015; Miller, 2000). 


\section{O papel das competências}

Uma evolução relevante da RBV, na perspectiva das competências, é apresentada por Teece, Pisano e Shuen (1997), os quais definem as competências e suas principais características, entre as quais se destaca a viscosidade: as competências não podem ser desenvolvidas rapidamente pelas organizações nem adquiridas no mercado ou facilmente substituídas (Teece, Pisano, \& Shuen, 1997). Essa abordagem identifica como estratégias organizacionais fundamentais tanto a valorização das capacidades específicas disponíveis quanto o desenvolvimento de novas capacidades, algumas das quais podem ter natureza intangível, a exemplo de novas habilidades gerenciais, reputação com clientes e fornecedores, maior conhecimento e know-how (Teece et al., 1997).

Zollo e Winter (2002) defendem que as competências se desenvolvem mediante um processo de aprendizagem, o qual consiste na acumulação de experiência mediante experimentação e repetição de tarefas semelhantes. Essas atividades desenvolvidas coletivamente em uma organização, de forma estável, tornam-se competências voltadas a definir e a aprimorar as rotinas operacionais. Winter (2003) define as competências organizacionais como rotinas altamente qualificadas que uma organização adota para coordenar suas atividades produtivas, perseguir seus objetivos-chave e resolver seus problemas, utilizando da melhor forma possível seus recursos. O mesmo autor ainda distingue, entre as competências de nível zero ou ordinárias, que permitem a uma organização ganhar a vida, e as competências dinâmicas, que são voltadas para a mudança de produto, processo, escala, clientes etc., favorecendo a criação de novas rotinas operacionais ou a adaptação daquelas existentes.

\section{Competências públicas}

As competências públicas consistem naquelas capacidades - específicas da administração pública - para regular, contratar, gerir e supervisar (Rangan et al., 2006), estabelecer normas e fazê-las cumprir, estruturar mecanismos de governança e coordenação (Mahoney et al., 2009). Para os fins desta pesquisa, as competências públicas foram analisadas em nível individual, pois se entende que, diante da homogeneidade de procedimentos existentes numa instituição pública, a fonte de heterogeneidade que influencia no desempenho dos contratos reside nas competências presentes em grau diferente entre os diversos servidores responsáveis (Cabral, 2017).

O trabalho de Andrews et al. (2015) sobre competências públicas sustenta que o conceito de capabilities, apesar de ter sido estudado principalmente em empresas privadas, pode ajudar a compreender a gestão dos serviços públicos, pois as entidades públicas dependem fortemente daquelas pessoas comprometidas a melhorar o desempenho organizacional. Dado que as competências distintivas de uma organização são formadas pelas práticas constituídas a partir das experiências acumuladas pelos membros da organização na resolução de problemas e na tomada de decisão, o tempo de permanência é um fator-chave para que a organização seja capaz de capturar os benefícios das capacidades desenvolvidas por seus funcionários mais estáveis. Essas capacidades incluem conhecimentos idiossincráticos, capital social e relações interpessoais, elementos estes considerados, numa organização pública, como recursos únicos, valiosos, raros e difíceis de imitar (Andrews, Beynon, \& McDermott, 2015). Nessa mesma linha, Brown e Potoski (2003) e Cabral (2017) destacam como a acumulação de experiência por parte dos agentes públicos favorece o desenvolvimento de conhecimentos e de capacidades tanto na gestão quanto no monitoramento de contratos. Adicionalmente, a forma como o processo licitatório é conduzido depende fortemente dos atores públicos encarregados de sua operacionalização (Decarolis, Giuffrida, Iossa, Mollisi, \& Spagnolo, 2017). Assim, as competências dos servidores responsáveis pela negociação de contratos (principalmente os pregoeiros) consistem, essencialmente, nas habilidades de selecionar, no menor tempo possível, fornecedores capazes de produzirem bens/, adequados às necessidades organizacionais, favorecer a concorrência entre licitantes e obter melhores termos contratuais, no tocante a preço e a prazo. Durante a fase de execução dos contratos, essas competências se referem à habilidade de fiscais administrativos e fiscais técnicos, respectivamente, administrarem de maneira produtiva as relações com as empresas e avaliarem os comportamentos destas, garantindo um constante alinhamento entre interesses públicos e privados (Cabral, 2017). Assim, além das competências de negociação de contratos, devem ser consideradas as 
competências de monitoramento (ou fiscalização), as quais são voltadas a limitar os comportamentos oportunistas dos múltiplos agentes envolvidos - a exemplo de corrupção, adoção de atitudes de freerider etc.- mediante apropriados mecanismos de incentivo e controle (Alchian \& Demsetz, 1972; Bolton \& Dewatripont, 2005; Dixit, 2002; Fama \& Jensen, 1983; Kim \& Mahoney, 2006), sendo desenhadas para verificar o respeito dos termos contratuais (Cabral, 2017). Esse aspecto é ainda mais relevante na prestação de serviços contínuos, caracterizados por elevada intensidade de capital humano.

Ainda sobre a importância do monitoramento, Girth (2012) analisa o uso de sanções como instrumento para responsabilizar pelo desempenho as prestadoras de serviços públicos. Dado que as decisões tomadas pelos gestores públicos influenciam no comportamento das empresas contratadas, é fundamental analisar as possíveis respostas dos primeiros, em caso de desempenho insatisfatório das segundas. Os agentes públicos, cujas decisões discricionárias são delimitadas pela legislação e pelas cláusulas contratuais, podem adotar medidas que variem entre não fazer nada, resolver a questão informalmente e punir o operador privado, mediante a aplicação de sanções nas suas várias gradações (Girth, 2012). Portanto, entende-se que, independentemente dos fatores que motivem as decisões por parte dos agentes públicos de sancionar ou não as empresas, é relevante, para os fins desta pesquisa, contemplar as competências de monitoramento.

Apesar das restrições burocráticas presentes no setor público (ineficiência na seleção, avaliação e demissão de pessoas, limites orçamentários etc.), a garantia de estabilidade reconhecida para os servidores públicos permite que estes acumulem experiência e conhecimentos ao longo do tempo. $\mathrm{O}$ estoque de experiência adquirido por eles, juntamente ao seu nível de formação, favorece a reconfiguração de recursos e a melhoria das rotinas organizacionais (Cabral, 2017). Mais especificamente, o tempo de permanência dos servidores responsáveis pela negociação ou contratação (pregoeiros), gestão (fiscais administrativos) e monitoramento (fiscais técnicos) dos contratos pode ser considerado um indicador relevante de experiência acumulada.

Assim:

$\mathbf{H}_{1}$ : Quanto maior o nível de competências públicas, menores os preços pagos pelo Estado na aquisição de serviços.

$\mathbf{H}_{2}$ : Quanto maior o nível de competências públicas, maior a qualidade de contratos de terceirização de serviços.

\section{Competências privadas}

As competências privadas, nesta pesquisa, foram analisadas em nível organizacional, pois as competências presentes em grau diferente entre as diversas prestadoras de serviço constituem uma fonte de heterogeneidade que influencia no desempenho dos contratos (Cabral, 2017). Neste sentido, de acordo com Rangan et al. (2006), as competências privadas são aquelas capacidades pelas quais uma empresa executa de forma eficiente o serviço no qual ela é especializada. Essas capacidades são apresentadas, ainda, como complementares às capacidades públicas. Segundo Cabral (2017), as competências de execução permitem que uma organização compatibilize suas necessidades com aquelas dos usuários a fim de oferecer certo grau de diferenciação e vantagem competitiva. Requisitos fundamentais para desenvolver essas competências consistem na acumulação de conhecimentos práticos (learning by doing) e na repetição frequente de práticas eficazes, combinadas com adequados conhecimentos de técnicas de gestão. Esse conjunto permite explorar os recursos organizacionais de maneira eficaz (Teece et al., 1997; Winter, 2003; Zollo \& Winter, 2002) e aumentar o potencial de criação de valor (Kivleniece \& Quelin, 2012).

Tais competências, desenvolvidas também graças a interações mais frequentes e próximas entre as partes, ajudam a superar problemas inerentes à incompletude contratual e a possíveis conflitos na aplicação das cláusulas contratuais. Portanto, a rigidez das rotinas burocráticas pode ser contornada mediante o estabelecimento de relações recíprocas mais construtivas (Cabral, 2017). Neste sentido, a experiência acumulada pelas empresas na prestação de serviços públicos pode permitir que estas 
desenvolvam conhecimentos voltados a compreender as necessidades peculiares dos gestores públicos e, na prática, ofereçam propostas conforme as especificações estabelecidas, competitivas e de alto valor agregado, garantindo o alinhamento dos interesses de ambas as partes e a satisfação do interesse público (Cabral, 2017; Reis \& Cabral, 2016).

No âmbito das competências privadas, outro componente relevante é constituído pelas capacidades financeiras. Segundo Domberger e Jensen (1997), a seleção de empresas privadas por parte dos gestores públicos não pode basear-se exclusivamente no preço, pois é necessário avaliar a experiência prévia das organizações e sua capacidade financeira, consideradas cruciais para o cumprimento das obrigações contratuais e para a retenção dos trabalhadores mais qualificados.

Dessa forma:

H3: Quanto maior o nível de competências privadas, menores os preços pagos pelo Estado na aquisição de serviços.

Spagnolo (2012) enfatiza a importância da reputação como fator capaz de influenciar fortemente as condutas do fornecedor e contribuir positivamente para melhorar o desempenho de contratos de terceirização de serviços públicos, especialmente em ambientes caracterizados por assimetrias informativas e interações frequentes entre as partes. Segundo Reis e Cabral (2016), a reputação pode ser definida como a avaliação da competência de uma organização em cumprir os requisitos qualitativos dos acordos de maneira satisfatória. Num contexto de interações frequentes entre agentes públicos fiscalizadores e executores privados, é provável que surjam incentivos implícitos ligados à reputação, reduzindo o risco de comportamentos oportunistas e induzindo a obtenção de resultados mais favoráveis para o poder público. Nessa linha, no âmbito de contratos de terceirização no setor público, o histórico prévio de boas condutas do fornecedor pode ser considerado um componente associado a competências superiores presentes no setor privado. Logo:

$\mathbf{H}_{4}$ : A existência de padrões superiores de competências no setor privado está associada ao maior desempenho em contratos de terceirização de serviços no âmbito do setor público.

\section{Procedimentos Metodológicos}

Os dados utilizados neste trabalho foram obtidos por meio de pesquisa documental, que consistiu em identificação, seleção e classificação, in loco, de documentos cartáceos e eletrônicos relativos a contratos de terceirização da Universidade Federal da Bahia (UFBA), organização pública voltada a atividades de ensino, pesquisa e extensão, sob a égide do Ministério da Educação do Brasil. Foram analisados contratos de serviços de recepção, portaria, vigilância, limpeza, transporte e manutenção, no período de 2002 a 2015. A amostra contemplou 167 observações, a totalidade de contratos assinados no período analisado, o que, além de eliminar qualquer suspeita de viés de seleção na formação da amostra, também assegura a devida transparência em relação aos protocolos de pesquisa adotados. Termos aditivos não foram analisados no âmbito da presente investigação.

O levantamento dos contratos e dos documentos correlatos não registrados no Sistema Integrado de Patrimônio, Administração e Contratos da UFBA (SIPAC) - referentes ao período de 2002 a 2009 necessitou de análise e seleção de aproximadamente 30 caixas, as quais continham processos de diferente natureza, pois o sistema de codificação adotado na instituição estudada não permite distinguir os processos a partir do número de protocolo adotado. Esse trabalho, que contou com o apoio da Coordenação de Arquivo e Documentação da UFBA (CAD), demandou um esforço considerável em termos de tempo.

Os dados coletados, da forma descrita acima, organizados em uma base de dados criada especificamente para a pesquisa, foram analisados mediante modelos estatísticos e utilizados, de forma 
exploratória, para entender o comportamento das competências no setor público Todas as variáveis foram medidas em função dos valores associados a cada caso da população observada (os contratos).

Os dados necessários para a pesquisa foram levantados recorrendo-se não somente aos contratos, mas também a outros documentos oriundos de diferentes fontes. Tais documentos incluem os históricos de sanções recebidas pelas empresas (registradas no Sistema Integrado de Administração de Serviços Gerais); balanços dos fornecedores e das atas de pregões (Sistema de Cadastramento Unificado de Fornecedores); históricos funcionais dos servidores públicos (registrados no Portal da Transparência); termos aditivos (Diário Oficial da União); portarias de designação de fiscais (disponíveis no arquivo central da UFBA), entre outros. Vale frisar que o acesso aos dados sobre fiscais técnicos e administrativos foi limitado devido à indisponibilidade de documentação oficial referente a muitas das designações realizadas entre 2002 e 2010, pois, nesse período, não raro, costumava-se designar os fiscais de contrato de prestação de serviços informalmente.

\section{Variáveis de desempenho}

O desempenho das relações contratuais foi avaliado mediante duas dimensões, custo e qualidade, as quais se encontram fundamentadas tanto em estudos de autores clássicos das teorias contratuais (Alchian \& Demsetz, 1972; Bolton \& Dewatripont, 2005; Williamson, 1996) quanto em pesquisas mais recentes, sobre as competências no âmbito do setor público (Cabral 2017; Cabral et al., 2013; Decarolis et al., 2017; Girth, 2012).

Para esta pesquisa, como indicador de custo, foi adotada a economia no valor dos contratos, calculada com base na diferença entre o valor estimado no pregão e o valor inicial do contrato, nos moldes do artigo de Reis e Cabral (2015) sobre o desempenho de pregões realizados por entidades públicas brasileiras. Quanto à qualidade, são contempladas as sanções recebidas ex post como proxies para medir a qualidade de contratos de serviços (Cabral, 2017; Cabral et al., 2013; Girth, 2012; Reis \& Cabral, 2016). Mais especificamente, foiutilizada uma variável dicotômica denominada dummy de sanções, a qual observa a existência, ou não, de sanções recebidas durante a execução do contrato, além de uma variável discreta denominada tipo de sanções, a qual mensura o nível de gravidade das sanções recebidas durante a vigência do contrato (advertência, multa, rescisão, suspensão temporária e inidoneidade para licitar e contratar).

\section{Variáveis explicativas}

As variáveis explicativas adotadas nesta pesquisa se referem às competências dos servidores públicos (nível individual) e das empresas privadas (nível organizacional).

No tocante às competências públicas, foram observadas as competências de pregoeiros, fiscais administrativos e fiscais técnicos, responsáveis respectivamente pela contratação, gestão e monitoramento dos contratos de serviços. Com base no marco teórico, as competências dos agentes públicos foram medidas por meio da coleta de dados sobre os anos de experiência no serviço público, o tipo de formação relacionado com o cargo exercido e a remuneração. Destaca-se que as variáveis relacionadas aos pregoeiros não são reportadas nas regressões operacionalizadas para analisar o desempenho ex post, pois não há nenhum tipo de influência desses profissionais na execução do trabalho de fiscalização. De igual sorte, não são utilizadas variáveis relacionadas aos fiscais dos contratos nas regressões ex ante, visto que não há influência desses servidores no processo de licitação, até mesmo porque tais profissionais somente são apontados após a assinatura do contrato.

No que diz respeito às competências privadas, foram adotadas as seguintes variáveis: anos de atividade da empresa, grau de experiência da empresa no setor público, liquidez geral, solvência geral e a dummy de sanções ex ante. A variável anos de atividade da empresa capta a quantidade de anos pelos quais o fornecedor atua no setor de atividade pela qual é contratado. A variável grau de experiência da empresa no setor público corresponde ao quociente entre os anos de atuação do fornecedor no setor público e seus anos de atuação no setor específico de atividade. Portanto, ambas as 
variáveis são utilizadas proxies para medir a experiência do fornecedor. Quanto às capacidades financeiras das empresas, foram utilizadas as variáveis liquidez geral e solvência geral, cuja utilização é prevista em lei. Mesmo sabendo que os dados dos balanços estão sujeitos a manipulações para melhorar a aparência das demonstrações contábeis - window dressing - (Iudícibus, 1994), destaca-se que essa prática é adotada indistintamente por organizações com características diferentes, portanto sua presença não altera os resultados das análises. Além disso, os dados dos balanços - entregues na fase de habilitação do processo licitatório - são os únicos dados oficiais disponíveis. Por fim, o histórico de sanções é uma dummy - relacionada à reputação - que indica a existência, ou não, de sanções recebidas ex ante, independentemente de que tenham sido cominadas pela UFBA ou por outra entidade.

\section{Variáveis de controle}

Foram utilizadas também quatro variáveis de controle a fim de avaliar os efeitos de outros fatores no desempenho, além das variáveis explicativas. A variável valor inicial do contrato mede o valor do serviço pactuado no instrumento contratual. Como forma de reduzir a elevada dispersão dos dados, foi calculado o logaritmo natural da variável original. A variável competidores mensura a quantidade de empresas participantes do processo licitatório (na maior parte dos casos, pregão) ou, em caso de contratação emergencial, de empresas que submeteram sua proposta à UFBA. Salienta-se que, para as modalidades de licitação diferentes de pregão, a pesquisa documental não permitiu acessar as atas correspondentes, portanto, os casos apresentam missing values. A mesma situação ocorreu em alguns casos de contratação emergencial, pois a documentação encontrada na CAD nem sempre disponibilizou os orçamentos das empresas concorrentes. Em consequência disso, reduziu-se mais ainda o número de casos contemplados nas estimativas referentes às variáveis dependentes. A variável tipo de serviço se refere à natureza do serviço prestado. Observa-se que, para facilitar a análise estatística dos dados, foram criadas quatro categorias: (a) a primeira, incluindo os serviços de recepção, portaria, limpeza e apoio administrativo/operacional; (b) a segunda correspondendo à vigilância; (c) a terceira abrangendo transporte e manutenção; e, por fim, (d) a quarta, referindo-se aos demais tipos de serviços. Em conclusão, a variável jaleco branco é uma dummy que assume valor $\mathbf{0}$ nos contratos celebrados anteriormente à deflagração da operação homônima da Polícia Federal (até novembro de 2007); e assume valor 1 nos contratos estipulados posteriormente (a partir de dezembro de 2007). O controle jaleco branco foi inserido nos modelos de regressão com o intuito de verificar se e em que medida fatores exógenos, tais como escândalos de corrupção largamente reportados pela mídia, podem afetar os resultados das estimativas. É oportuno ressaltar que a Operação Jaleco Branco desmontou uma quadrilha que fraudava licitações públicas de serviços de limpeza e vigilância prestados para a UFBA e para outras organizações públicas (A Tarde, 2007).

Acredita-se que as variáveis de controle adotadas podem auxiliar a mitigar problemas relacionados à endogeneidade de variáveis não observáveis e eventuais correlações entre observáveis com termos de erro (Wooldridge, 2002), reduzindo, assim, a possibilidade de estimadores inconsistentes ou enviesados. Infelizmente, não foi possível identificar variáveis instrumentais que permitissem simular modelos em dois estágios.

A Tabela 1, a seguir, demonstra as variáveis utilizadas em nossas estimativas. 
Tabela 1

\section{Descrição das Variáveis Utilizadas}

\begin{tabular}{|c|c|c|c|c|}
\hline Conceitos & Dimensões & Componentes & Variáveis & Referências \\
\hline \multirow[t]{2}{*}{$\begin{array}{l}\text { Desempenho } \\
\text { das relações } \\
\text { contratuais }(\mathrm{Y})\end{array}$} & Custo & $\begin{array}{l}\text { Economia no valor } \\
\text { do contrato }\end{array}$ & $\begin{array}{l}\text { - Diferença entre valor } \\
\text { estimado e valor inicial } \\
\text { do contrato }\end{array}$ & $\begin{array}{l}\text { Cabral (2017); Reis e } \\
\text { Cabral }(2015,2016)\end{array}$ \\
\hline & Qualidade & Sanções ex post & $\begin{array}{l}\text { - Dummy de sanções } \\
\text { - Tipo de sanções }\end{array}$ & $\begin{array}{l}\text { Alchian e Demsetz } \\
\text { (1972); Bolton e } \\
\text { Dewatripont, (2005); } \\
\text { Cabral (2017); Cabral e } \\
\text { Azevedo (2008); Cabral, } \\
\text { Lazzarini e Azevedo } \\
\text { (2013); Girth (2012); } \\
\text { Reis e Cabral (2016); } \\
\text { Williamson (1996) }\end{array}$ \\
\hline \multirow[t]{6}{*}{ Competências (X) } & Competências & Remuneração & - Remuneração de Fiscal & \multirow{3}{*}{$\begin{array}{l}\text { Andrews et al. (2015); } \\
\text { Brown e Potoski (2003); } \\
\text { Cabral (2017); Cabral et } \\
\text { al., (2013); Decarolis, } \\
\text { Giuffrida, Iossa, Mollisi, } \\
\text { e Spagnolo (2017); } \\
\text { Williamson (1999) }\end{array}$} \\
\hline & Publicas & Formação & $\begin{array}{l}\text { - Nível de formação de } \\
\text { Pregoeiro e Fiscal }\end{array}$ & \\
\hline & & Experiência & $\begin{array}{l}\text { - Anos de atuação de } \\
\text { Pregoeiro e Fiscal no } \\
\text { serviço público }\end{array}$ & \\
\hline & \multirow[t]{3}{*}{$\begin{array}{l}\text { Competências } \\
\text { Privadas }\end{array}$} & Experiência & $\begin{array}{l}\text { - Anos de experiência da } \\
\text { empresa na atividade } \\
\text { - Grau de experiência da } \\
\text { empresa no setor } \\
\text { público }\end{array}$ & $\begin{array}{l}\text { Cabral (2017); } \\
\text { Kivleniece e Quelin } \\
(2012) ; \text { Reis e Cabral } \\
(2015,2016) \text {; Teece } \text { et } \\
\text { al. }(1997) \text {; Winter } \\
(2003) \text {; Zollo e Winter } \\
(2002)\end{array}$ \\
\hline & & Reputação & $\begin{array}{l}\text { - Dummy de histórico de } \\
\text { sanções (ex ante) }\end{array}$ & $\begin{array}{l}\text { Alchian e Demsetz, } \\
\text { (1972); Cabral e } \\
\text { Saussier (2013); Dixit } \\
\text { (2002); Girth (2012); } \\
\text { Reis e Cabral (2016); } \\
\text { Spagnolo (2012) }\end{array}$ \\
\hline & & $\begin{array}{l}\text { Capacidades } \\
\text { financeiras }\end{array}$ & $\begin{array}{l}\text { - Liquidez geral } \\
\text { - Solvência geral }\end{array}$ & $\begin{array}{l}\text { Beck e Demirguc-Kunt } \\
\text { (2006); Domberger e } \\
\text { Jensen (1997) }\end{array}$ \\
\hline
\end{tabular}

Nota. Fonte: Elaborada pelos autores.

\section{Métodos de estimação}

Os dados foram analisados mediante modelos estatísticos definidos de acordo com os tipos de variáveis dependentes estudadas (Hair, Black, Babin, Anderson, \& Tatham, 2009). Foram operacionalizados os seguintes modelos de regressão: mínimos quadrados ponderados (MQP) para a variável dependente economia; probit para a dummy de sanções; e probit ordenado para a variável tipo de sanções. Em primeiro lugar, para estimar a economia no valor do contrato foi aplicado um modelo de MQP, que permitiu atribuir pesos diferenciados às observações com o intuito de corrigir a heterocedasticidade - isto é, a variância dos erros - dos resíduos (Gujarati, 2006; Wooldridge, 2013). Mais precisamente, esseprocedimento, conhecido também como regressão robusta, prevê a atribuição de pesos inversamente proporcionais à heterocedasticidade, adotando consequentemente erros-padrão robustos, conhecidos também como erros-padrão robustos de White (Gujarati, 2006; White, 1980; 
Wooldridge, 2013). Em segundo lugar, foi estimado um modelo não linear de escolha qualitativa (probit), para avaliar os efeitos das competências sobre a probabilidade de os contratos receberem sanções durante sua execução. Em conclusão, foi estimado um modelo não linear probit ordenado com o objetivo de avaliar os efeitos das competências sobre a probabilidade de os contratos estarem sujeitos a sanções mais graves. Esse modelo, considerado uma extensão do modelo probit, deve ser utilizado quando a variável dependente possui mais de duas categorias ordenadas (Gujarati, 2006; Liu, 2016). Em ambos os modelos (probit e probit ordenado), foram operacionalizadas regressões com erros-padrão robustos de White (1980) para corrigir problemas de heterocedasticidade e aumentar o grau de confiabilidade dos resultados obtidos (Gujarati, 2006).

Adicionalmente, devido à heterogeneidade dos contratos analisados nesta pesquisa e a fim de garantir uma maior robustez dos resultados das regressões, foram introduzidos, para todos os conjuntos de regressões, efeitos fixos (EF) de tempo com a inserção de dummies de anos dos contratos. Em que pesem as limitações impostas pela nossa base de dados única em termos de graus de liberdade, tais EF foram operacionalizados também com o intuito de reduzir alguns vieses e problemas de simultaneidade e endogeneidade. Introduzidos os $\mathrm{EF}$ de tempo, os três conjuntos de regressões alcançaram a convergência, aumentaram o potencial explicativo das variáveis independentes e reforçaram a robustez dos resultados das estimações.

Para a validação dos métodos de estimação, foram utilizados os seguintes diagnósticos, respectivamente: o teste $\mathrm{F}$ para MQP e o teste de Wald (qui-quadrado) para probit/probit ordenado. Destaca-se que o teste de Wald é um método similar ao teste F, mas sua aplicação pode ser estendida para a validação de modelos não lineares, e o próprio teste se caracteriza por requerer a estimação de um único modelo e possuir uma distribuição qui-quadrado assintótica (Wooldridge, 2013).

\section{Resultados e Discussão}

A Tabela 2 mostra as estatísticas descritivas das variáveis, especificando a forma como tais variáveis foram mensuradas.

Tabela 2

Estatísticas Descritivas

\begin{tabular}{llccccc}
\hline Nome & Descrição & Casos & Média & $\begin{array}{c}\text { Desvio } \\
\text { Padrão }\end{array}$ & Mínimo & Máximo \\
\hline Variáveis Dependentes & & & & & \\
\hline CUSTO & & & & & & \\
\hline economia & $\begin{array}{l}\text { Diferença entre valor estimado } \\
\text { no pregão e valor inicial do } \\
\text { contrato }\end{array}$ & 77 & 865.538 & $1,294 \mathrm{e}+06$ & -592.474 & $6,017 \mathrm{e}+06$ \\
\hline QUALIDADE & & 165 & 0,188 & 0,392 & 0 & 1 \\
dummy sanc & $\begin{array}{l}\text { Dummy igual a 1 se há alguma } \\
\text { sanção ex post. }\end{array}$ & 165 & 0,248 & 0,557 & 0 & 2 \\
\hline tipo sanc & $\begin{array}{l}\text { Variável igual a 0 se não houve } \\
\text { sanções; 1 para } \\
\text { advertência/multa; 2 para } \\
\text { rescisão, suspensão e } \\
\text { inidoneidade. }\end{array}$ & 165 & & & & \\
\hline
\end{tabular}


Tabela 2 (continuação)

\begin{tabular}{|c|c|c|c|c|c|c|}
\hline Nome & Descrição & Casos & Média & $\begin{array}{l}\text { Desvio } \\
\text { Padrão }\end{array}$ & Mínimo & Máximo \\
\hline \multicolumn{7}{|c|}{ Variáveis Explicativas } \\
\hline \multicolumn{7}{|c|}{ COMPETÊNCIAS PÚBLICAS } \\
\hline form preg & $\begin{array}{l}\text { Dummy igual a } 1 \text { se a formação } \\
\text { corresponde a nível técnico ou } \\
\text { graduação. }\end{array}$ & 79 & 0,430 & 0,498 & 0 & 1 \\
\hline anos preg & $\begin{array}{l}\text { Anos de atuação do pregoeiro } \\
\text { no serviço público }\end{array}$ & 79 & 12,68 & 10,00 & 2 & 30 \\
\hline $\begin{array}{l}\text { remun fisc adm } \\
(\mathrm{R} \$)\end{array}$ & $\begin{array}{l}\text { Vencimento mensal + gratificação } \\
\text { do fiscal administrativo }\end{array}$ & 133 & 4.516 & 3.238 & 1.008 & 13.569 \\
\hline form fisc adm & $\begin{array}{l}\text { Dummy igual a 1, se a formação } \\
\text { corresponde a nível técnico ou } \\
\text { graduação }\end{array}$ & 133 & 0,414 & 0,494 & 0 & 1 \\
\hline anos fisc adm & $\begin{array}{l}\text { Anos de atuação do fiscal } \\
\text { administrativo no serviço público }\end{array}$ & 133 & 16,83 & 11,66 & 0 & 38 \\
\hline $\begin{array}{l}\text { remun fisc tecn } \\
(\mathrm{R} \$)\end{array}$ & $\begin{array}{l}\text { Vencimento mensal + } \\
\text { gratificação do fiscal técnico }\end{array}$ & 119 & 5.104 & 3.919 & 1.008 & 13.668 \\
\hline form fisc tecn & $\begin{array}{l}\text { Dummy igual a 1, se a formação } \\
\text { corresponde a nível técnico ou } \\
\text { graduação }\end{array}$ & 119 & 0,403 & 0,493 & 0 & 1 \\
\hline anos fisc tecn & $\begin{array}{l}\text { Anos de atuação do fiscal } \\
\text { técnico no serviço público }\end{array}$ & 119 & 21,45 & 10,39 & 0 & 41 \\
\hline \multicolumn{7}{|c|}{ COMPETENNCIAS PRIVADAS } \\
\hline anos empresa & $\begin{array}{l}\text { Anos de atuação da empresa no } \\
\text { seu setor da atividade }\end{array}$ & 165 & 15,57 & 11,15 & 2 & 84 \\
\hline exper public & $\begin{array}{l}\text { Quociente entre anos de atuação } \\
\text { da empresa no setor público e } \\
\text { no seu setor }\end{array}$ & 165 & 0,452 & 0,303 & 0 & 1 \\
\hline histórico sanc & $\begin{array}{l}\text { Dummy igual a } 1, \text { em caso de } \\
\text { sanções recebidas ex ante }\end{array}$ & 165 & 0,442 & 0,498 & 0 & 1 \\
\hline liquid geral & Liquidez geral da empresa & 163 & 4,250 & 19,83 & 0,290 & 240,4 \\
\hline solv geral & Solvência geral da empresa & 163 & 25,45 & 83,77 & 1 & 359,1 \\
\hline \multicolumn{7}{|c|}{ Variáveis de Controle } \\
\hline $\begin{array}{l}\text { valor inicial } \\
(\mathrm{R} \$)\end{array}$ & Valor inicial do contrato & 164 & $2,163 \mathrm{e}+06$ & $3,213 \mathrm{e}+06$ & 3.960 & $1,975 \mathrm{e}+07$ \\
\hline competidores & $\begin{array}{l}\text { Quantidade de empresas } \\
\text { participantes da licitação }\end{array}$ & 102 & 14,44 & 15,70 & 1 & 71 \\
\hline tipo serviço & $\begin{array}{l}\text { Variável igual a } 1 \text { para } \\
\text { recepção, portaria, limpeza e } \\
\text { apoio adm/operacional; } 2 \text { para } \\
\text { vigilância; } 3 \text { para transporte e } \\
\text { manutenção; } 0 \text { para outros } \\
\text { serviços }\end{array}$ & 167 & 1,760 & 1,142 & 0 & 3 \\
\hline jaleco branco & $\begin{array}{l}\text { Dummy igual a } 0 \text { para contrato } \\
\text { estipulado até novembro de } \\
\text { 2007; igual a } 1 \text { para contrato } \\
\text { estipulado a partir de dezembro } \\
\text { de } 2007\end{array}$ & 167 & 0,617 & 0,488 & 0 & 1 \\
\hline
\end{tabular}

Nota. Fonte: Resultados da pesquisa.

RAC, Rio de Janeiro, v. 22, n. 4, art. 2, pp. 487-509, julho/agosto, 2018 www.anpad.org.br/rac 
Os 167 contratos de serviços tratam de serviços diversos, prestados por 83 empresas diferentes ao longo dos 14 anos do período escolhido. Em média, 14,44 empresas participaram das licitações, sendo que o pregão mais concorrido contemplou a participação de 71 fornecedores.

Com relação às variáveis de desempenho, a economia alcança, em média, um valor em torno de $\mathrm{R} \$ 865,00$, apresentando elevada dispersão. Em termos percentuais, a média da economia foi de 5,6\%, bem abaixo de 20,3\%, média nacional das compras públicas no período de 2008 a 2014 (Ministério do Planejamento, 2015). Quanto à qualidade, $18,8 \%$ dos contratos receberam sanções, sendo que $12,7 \%$ do total receberam advertência ou multa e cerca de $6,1 \%$ do total obtiveram uma sanção mais grave.

Quanto às competências públicas, a remuneração apresenta elevada dispersão, em especial, no caso dos fiscais, oscilando entre $\mathrm{R} \$ 1.000,00$ e $\mathrm{R} \$ 13.600,00$. Essa heterogeneidade se deve ao fato de que, no período estudado, o salário mínimo evoluiu de R \$200,00 para R \$ 788,00 (Previdência Social, 2017). Os fiscais apresentam mais anos de atuação no serviço público - 17 anos para os administrativos e 21,5 anos para os técnicos - em comparação com os pregoeiros (13 anos). Quanto à formação, $40 \%$ a $43 \%$ dos servidores possuem cargo associado ao nível técnico/graduação. Com relação às competências privadas, as empresas possuem mediamente 15,5 anos de atuação no setor de atividade, com desvio padrão superior a 11 anos. Essas firmas possuem experiência pública correspondente a 45,2\% de sua idade, registrando uma média de 6 anos. A liquidez geral apresenta um valor médio de 4,25 e denota uma dispersão quase cinco vezes maior que a média. Os valores da solvência geral apresentam uma média de 25,45, com um desvio padrão mais de três vezes maior que a média. Quanto ao histórico de sanções, os fornecedores sofreram penalidades em $44,2 \%$ dos casos, média bem superior àquela das sanções ex post (menos de 20\%).

Sucessivamente, foi estudada a correlação entre as variáveis, com o intuito de verificar a existência de multicolinearidade (Wooldridge, 2013). A matriz - não reportada aqui, mas disponível a pedido - mostra que existe forte correlação (acima de 65\%) entre formação e anos atividade do pregoeiro. Há também forte correlação entre tipo e dummy de sanções (comportamento esperado que não afeta os resultados). Para avaliar os efeitos das competências públicas no custo, foram mantidas as variáveis formação e anos de atividade do pregoeiro, apesar de estarem negativamente correlacionadas entre si $(-68 \%)$.

A Tabela 3, a seguir, reporta os resultados dos modelos estimados para as três variáveis de desempenho: os modelos 1 e 2 analisam, por meio de MQP, os efeitos das competências na economia; os modelos 3 e 4 estudam, por meio de probit, os efeitos das competências na dummy de sanções; e os modelos 5 e 6 avaliam, por meio de probit ordenado, os efeitos das competências no tipo de sanções. Para cada conjunto de regressões, o segundo modelo é sempre operacionalizado com efeitos fixos (EF) de tempo. 
Tabela 3

Efeitos de Competências Públicas e Privadas no Custo e na Qualidade

\begin{tabular}{|c|c|c|c|c|c|c|c|}
\hline & & \\
\hline & & Modelo 1 & Modelo 2 & Modelo 3 & Modelo 4 & Modelo 5 & Modelo 6 \\
\hline & & MQP & MQP & Probit & Probit & Probit Ord & Probit Ord \\
\hline & Variáveis & economia & economia & $\begin{array}{l}\text { dummy } \\
\text { sanc }\end{array}$ & $\begin{array}{l}\text { dummy } \\
\text { sanc }\end{array}$ & tipo sanc & tipo sanc \\
\hline \multirow{16}{*}{$\begin{array}{l}\text { Competências } \\
\text { Públicas }\end{array}$} & form preg & 232.729 & 310.936 & & & & \\
\hline & & $(333.645)$ & (380.119) & & & & \\
\hline & anos preg & -4.472 & -18.231 & & & & \\
\hline & & (11.093) & $(26.252)$ & & & & \\
\hline & $\begin{array}{l}\log (\text { remun fisc } \\
\text { adm) }\end{array}$ & & & $1,212^{*}$ & 0,246 & $-0,183$ & $-1,492$ \\
\hline & & & & $(0,679)$ & $(1,327)$ & $(0,669)$ & $(1,055)$ \\
\hline & form fisc adm & & & $-1,417^{*}$ & $-2,913 * *$ & $-0,514$ & $-0,350$ \\
\hline & & & & $(0,732)$ & $(1,170)$ & $(0,524)$ & $(0,533)$ \\
\hline & anos fisc adm & & & $-0,0415$ & $-0,0736$ & $-0,00341$ & 0,000930 \\
\hline & & & & $(0,0306)$ & $(0,0527)$ & $(0,0254)$ & $(0,0344)$ \\
\hline & $\begin{array}{l}\log \text { (remun fisc } \\
\text { tecn) }\end{array}$ & & & $-0,730$ & $-5,199 * * *$ & $-0,473$ & $-2,837 * *$ \\
\hline & & & & $(0,519)$ & $(1,998)$ & $(0,484)$ & $(1,137)$ \\
\hline & form fisc tecn & & & 1,214 & $5,776 * * *$ & 0,882 & $2,993 * *$ \\
\hline & & & & $(0,881)$ & $(1,832)$ & $(0,717)$ & $(1,344)$ \\
\hline & anos fisc tecn & & & $-0,0416$ & $-0,0161$ & $-0,0250$ & $-0,0186$ \\
\hline & & & & $(0,0311)$ & $(0,0286)$ & $(0,0219)$ & $(0,0249)$ \\
\hline \multirow{10}{*}{$\begin{array}{l}\text { Competências } \\
\text { Privadas }\end{array}$} & anos empresa & -9.026 & -20.869 & $-0,0658 * *$ & $-0,113 * *$ & $-0,0346$ & $-0,0448$ \\
\hline & & (17.268) & $(14.873)$ & $(0,0323)$ & $(0,0559)$ & $(0,0284)$ & $(0,0385)$ \\
\hline & exper public & 319.181 & 448.753 & $-3,047 * *$ & $-9,333 * * *$ & $-2,047 * *$ & $-5,037 * *$ \\
\hline & & $(398.839)$ & $(459.458)$ & $(1,277)$ & $(2,915)$ & $(0,952)$ & $(2,184)$ \\
\hline & histórico sanc & 187.494 & 74.833 & 0,609 & $2,363 *$ & 0,551 & 1,379 \\
\hline & & $(202.211)$ & (204.857) & $(0,565)$ & $(1,239)$ & $(0,529)$ & $(0,892)$ \\
\hline & $\log$ (liquid geral) & $-729,815^{* * *}$ & $-810.909 * * *$ & $-0,0338$ & $-0,731$ & $-0,273$ & $-1,331$ \\
\hline & & $(205.385)$ & $(225.833)$ & $(0,551)$ & $(1,179)$ & $(0,388)$ & $(0,829)$ \\
\hline & $\log ($ solv geral) & 309.616 & $438.870 *$ & $-0,744$ & $-1,793^{*}$ & $-0,497$ & $-0,915$ \\
\hline & & $(244.893)$ & $(245.357)$ & $(0,586)$ & $(1,040)$ & $(0,433)$ & $(0,746)$ \\
\hline
\end{tabular}


Tabela 3 (continuação)

\begin{tabular}{|c|c|c|c|c|c|c|c|}
\hline & & \\
\hline & & Modelo 1 & Modelo 2 & Modelo 3 & Modelo 4 & Modelo 5 & Modelo 6 \\
\hline & & MQP & MQP & Probit & Probit & Probit Ord & Probit Ord \\
\hline & Variáveis & economia & economia & $\begin{array}{l}\text { dummy } \\
\text { sanc }\end{array}$ & $\begin{array}{l}\text { dummy } \\
\text { sanc }\end{array}$ & tipo sanc & tipo sanc \\
\hline \multirow[t]{8}{*}{ Controles } & $\log ($ valor inicial $)$ & $351.659 * * *$ & $330.978 * * *$ & $1,007 * * *$ & $2,464 * * *$ & $0,711 * * *$ & $1,069^{* * * *}$ \\
\hline & & $(94.449)$ & (98.584) & $(0,271)$ & $(0,710)$ & $(0,193)$ & $(0,360)$ \\
\hline & competid & 10.537 & 11.352 & $-0,000972$ & $-0,00935$ & 0,00113 & 0,0215 \\
\hline & & (9.032) & (10.733) & $(0,0198)$ & $(0,0290)$ & $(0,0176)$ & $(0,0214)$ \\
\hline & tipo serviço & 124.471 & 136.625 & $-0,501 * *$ & $-1,489 * * *$ & $-0,361 * *$ & $-0,949 * * *$ \\
\hline & & $(107.420)$ & (106.018) & $(0,230)$ & $(0,511)$ & $(0,175)$ & $(0,331)$ \\
\hline & jaleco branco & -240.341 &,$- 305 \mathrm{e}+06^{* *}$ & $-0,969$ & 1,956 & 0,425 & 2,759 \\
\hline & & $(296.419)$ & (599.713) & $(0,903)$ & $(1,946)$ & $(0,795)$ & $(2,053)$ \\
\hline \multirow[t]{4}{*}{ Efeitos Fixos } & ano & Não & Sim & Não & Sim & Não & Sim \\
\hline & $\mathrm{N}$ & 74 & 74 & 67 & 67 & 67 & 67 \\
\hline & Teste F/Wald & $* * *$ & $* * *$ & $* * *$ & $* * *$ & $* * *$ & $* * *$ \\
\hline & R-quadrado & 0,423 & 0,551 & & & & \\
\hline
\end{tabular}

Nota. Fonte: Resultados da pesquisa.

O símbolo de $* * *$ indica $\mathrm{p}<0,01 ; * *$ indica $\mathrm{p}<0,05$; * indica $\mathrm{p}<0,1$. Erros-padrão robustos em parênteses.

\section{Efeitos no custo}

No tocante às competências públicas, os modelos 1 e 2 mostram que a formação e os anos de atuação do pregoeiro não possuem influência significativa na economia: pregoeiros com melhor formação e mais experiência não conseguem ser mais eficazes na negociação com as empresas. Esses resultados não suportam a $\mathrm{H}_{1}$ e não estão alinhados com as conclusões de pesquisas recentes, segundo as quais agentes públicos mais qualificados podem estimular a competitividade dos leilões públicos e gerar economia para o erário (Cabral, 2017). Pode-se supor que a ausência de efeitos das competências dos pregoeiros nos preços dos contratos está relacionada com os atributos da única entidade escolhida para esta pesquisa ou que os contratos analisados estão associados a um mercado caracterizado por baixa competição e elevada concentração da oferta de serviços em poucas empresas. A fim de respaldar a compreensão do mercado e dos comportamentos de seus atores, foram coletadas evidências por meio de interações junto a gestores da UFBA. Segundo eles, um número reduzido de empresários fecharia acordos entre si, compartilhando informações reservadas e limitando o acesso de potenciais concorrentes. Portanto, diante de um ambiente pouco competitivo, as competências dos pregoeiros se tornariam ineficazes, frustrando seu potencial para reduzir os preços dos serviços.

Quanto às competências privadas, os modelos 1 e 2 reportam que a liquidez geral das empresas possui uma influência significativa $(\mathrm{p}<0,01)$ e negativa sobre a economia, confirmada com a introdução de EF de tempo. Pode se admitir que empresas com melhores índices de liquidez tendem a não ceder nas negociações, mantendo o valor dos lances e aceitando o risco de não vencer a licitação. Entende-se que esse tipo de empresas - geralmente de médio e grande porte - são mais propensas a elaborar propostas econômico-financeiras coerentes com seus custos e sustentáveis durante a execução do contrato; consequentemente, preferem abrir mão de pregões menos atraentes, reduzindo, assim, o nível de competição da licitação (Reis, 2016; Tadelis, 2012). Pelo contrário, empresas com problemas de liquidez poderiam ver-se propensas a aceitar propostas menos sustentáveis, assumindo o risco de reduzirem sua sustentabilidade financeira na execução do contrato. 
Nas entrevistas com pregoeiros da UFBA, confirmou-se que firmas mais sólidas possuem capacidade para traduzir seus custos com precisão em suas propostas, mostrando certa resistência em aceitar descontos. Nos depoimentos coletados, foi colocado o exemplo de uma empresa de vigilância bastante intransigente na fase de negociação, pontual e comprometida na execução do contrato. Além disso, foram citados exemplos de empresas menos estruturadas, mais flexíveis na negociação, mas caracterizadas por fortes limitações na operação dos serviços. Foi colocado também que, frequentemente, empresas mais consolidadas atuam promovendo cartel com outros fornecedores, criando empresas de fachada e limitando a participação de outras firmas nos pregões, com o intuito de reduzir a concorrência e praticar preços abusivos. A influência negativa da liquidez geral das empresas na economia contraria a terceira hipótese de pesquisa $\left(\mathrm{H}_{3}\right)$, mas abre uma linha interessante de investigação para futuros trabalhos.

\section{Efeitos na qualidade}

Quanto às competências públicas, o modelo 4 - estimado com EF de tempo - mostra, por um lado, influência significativa e negativa da formação do fiscal administrativo $(\mathrm{p}<0.05)$ e da remuneração do fiscal técnico $(\mathrm{p}<0.01)$ na dummy de sanções ex post. Por outro lado, há uma influência positiva da formação do fiscal técnico $(\mathrm{p}<0.01)$. As variáveis associadas à formação desses profissionais possuem, portanto, um comportamento contraditório. No caso da formação, tal fenômeno, em parcial contradição com a $\mathrm{H}_{2}$, pode ser explicado se admitir-se que fiscais técnicos com formação superior sejam mais rigorosos na fiscalização, resultando num aumento da incidência de sanções e numa aparente redução da qualidade dos contratos (Cabral, 2017). Em alternativa, pode se supor que fiscais melhor formados sejam alocados pela administração pública no monitoramento de contratos mais sujeitos a receberem sanções. No geral, os resultados dessas estimações corroboram parcialmente com $\mathrm{H}_{2}$ : fiscais administrativos mais qualificados e fiscais técnicos melhor remunerados seriam capazes de melhorar o desempenho qualitativo dos contratos (Brown \& Potoski, 2003; Cabral, 2017).

Além disso, no que diz respeito à remuneração, é possível constatar que, no setor público, um maior salário do agente público não necessariamente corresponde a um maior grau de competência. De acordo com Williamson (1999), as organizações públicas são caracterizadas por baixos incentivos, procedimentos rígidos e estabilidade do emprego para seu pessoal. Os funcionários públicos, os quais podem ser demitidos somente nos casos previstos em lei, são remunerados e promovidos em função dos anos de permanência no cargo e não por sua produtividade (Cabral \& Lazzarini, 2015). Por conseguinte, os profissionais acima mencionados não estimulados a alcançar níveis superiores de desempenho, podem se adaptar a desempenhar suas funções aplicando à letra rotinas institucionais, mas atuando de forma superficial, indolente e desinteressada (Williamson, 1999). À luz disso, a menor probabilidade de haver sanções ex post, no caso de fiscais técnicos com retribuição mais elevada, pode ser interpretada como uma menor propensão a aplicar sanções a servidores públicos bem remunerados, mas, sim, àqueles pouco motivados. Ademais, diante de restrições financeiras, o agente público pode se sentir desencorajado a aplicar punições, especialmente quando o custo da eventual rescisão é maior que o benefício de contratar outras empresas (Girth, 2012), especialmente quando eventuais segundas classificadas apresentem características similares àquelas da empresa vencedora.

Quanto às competências privadas, conforme ilustrado pelos modelos 3 e 4 , as variáveis anos de atuação da empresa no setor da atividade e grau de experiência da empresa no setor público possuem efeitos negativos e significativos $(\mathrm{p}<0.05$ e $\mathrm{p}<0.01)$ na probabilidade de que sanções sejam cominadas ex post, corroborando a $\mathrm{H}_{4}$. Portanto, infere-se que empresas mais experientes e com maiores conhecimentos sobre as necessidades peculiares do setor público alcançam níveis de qualidade superiores na prestação de serviços (Cabral, 2017).

O modelo 6 registra efeitos significativos e negativos da remuneração do fiscal técnico $(\mathrm{p}<0.05)$ na probabilidade de os contratos receberem sanções mais graves, confirmando a $\mathrm{H}_{2}$. Esse efeito é muito robusto (estimado com EF de tempo), porém, analogamente ao que foi colocado a propósito da dummy de sanções ex post, não indica necessariamente uma influência positiva das competências de servidores melhor remunerados nos indicadores de qualidade. Quanto à formação do fiscal técnico, os resultados 
apresentados no modelo 6 confirmam uma associação positiva e significativa $(p<0,05)$ com a probabilidade de haver sanções mais graves. No caso analisado, a explicação pode ser similar àquela apresentada a propósito da dummy de sanções ex post: fiscais técnicos mais qualificados podem sancionar mais severamente as empresas (Cabral, 2017), ou a administração pública pode servir-se de fiscais técnicos melhor qualificados para lidar com contratos mais problemáticos.

Quanto às competências privadas, conforme ilustrado nos modelos 5 e 6, a um maior grau de experiência das empresas no setor público corresponde uma menor probabilidade de haver sanções mais graves $(\mathrm{p}<0.05)$, corroborando a $\mathrm{H}_{4}$. Aparentemente, as empresas mais experientes e com maiores conhecimentos das especificidades do setor público são menos propensas a receberem sanções mais graves ao longo da execução do contrato. Comparando os resultados reportados pelos conjuntos de regressões probit (modelos $3 \mathrm{e} 4$ ) com aqueles apresentados nos conjuntos de regressões probit ordenado (modelos 5 e 6), verifica-se que, no segundo caso, os efeitos da formação do fiscal administrativo e dos anos de atuação da empresa no setor de atividade já não são significativos e que os efeitos da remuneração e formação do fiscal técnico se tornam menos significativos, mostrando que, em presença de imperfeições do ambiente institucional (cartelização, conluios, baixos incentivos), as competências públicas e privadas perdem parte de seu impacto na qualidade dos contratos.

\section{Efeitos das variáveis de controle}

Além dos efeitos significativos positivos do valor inicial do contrato em todas as variáveis de desempenho $(\mathrm{p}<0,01)$ e negativos do tipo de serviço nas sanções ex post $(\mathrm{p}<0,01$ nos modelos 4 e 6$)$, merece destacar que o número de competidores não possui efeitos significativos no custo nem na qualidade, em contradição com os estudos recentes de Reis e Cabral $(2015,2016)$ e de Cabral (2017). Não obstante os dados apresentem uma média de 14,44 licitantes, a estrutura de mercado se mostra incapaz de estimular a concorrência entre empresas. É possível supor que tenha havido uma concentração elevada de firmas nas mãos de poucos empresários com formação de cartel voltada ao superfaturamento e à utilização de empresa de fachada, como revelado pela Operação Jaleco Branco (A Tarde, 2007; Tribuna da Bahia, 2009). Conforme colocado nas entrevistas, esse mercado, com baixa competição e escassa heterogeneidade entre as empresas, pode nivelar para baixo a qualidade dos serviços, ofertados a preços elevados, especialmente se comparados com o valor agregado produzido. Mais especificamente, a variável de controle jaleco branco mostra efeitos negativos modestos sobre a economia no valor dos contratos $(\mathrm{p}<0,05)$; por outro lado, não há efeitos significativos sobre os indicadores de qualidade, devido provavelmente à elevada incidência de missing values nas variáveis associadas aos fiscais dos contratos estipulados até 2010. A influência da dummy jaleco branco nos custos pode ser interpretada no sentido de que os contratos estipulados após a divulgação do escândalo permitiram selecionar empresas menos propensas a reduzir o preço nos pregões para posteriormente obter aditivos contratuais.

A Tabela 4 resume os resultados e suas possíveis explicações para cada hipótese de pesquisa. 
Tabela 4

\section{Resumo dos Resultados e Avaliação das Hipóteses de Pesquisa}

\begin{tabular}{|c|c|c|}
\hline Hipóteses & Resultados & Possíveis explicações \\
\hline $\begin{array}{l}\text { H}_{1} \text { : Quanto maior o nível de } \\
\text { competências públicas, menores os } \\
\text { preços pagos pelo Estado na } \\
\text { aquisição de serviços. }\end{array}$ & $\begin{array}{l}\text { Não suportada } \\
\text { Não há efeitos significativos das } \\
\text { competências do pregoeiro na } \\
\text { economia. }\end{array}$ & $\begin{array}{l}\text { Diante de baixa competição e da } \\
\text { cartelização, as competências dos } \\
\text { pregoeiros podem se tornar } \\
\text { ineficazes na negociação de } \\
\text { contratos. }\end{array}$ \\
\hline
\end{tabular}

H2: Quanto maior o nível de competências públicas, maior a qualidade de contratos de terceirização de serviços.

\section{Parcialmente suportada \\ Efeitos na dummy de sanções:}

Efeitos negativos da formação do fiscal administrativo e da remuneração do fiscal técnico; efeitos positivos da formação do fiscal técnico

Efeitos no tipo de sanções:

Efeitos positivos da formação do fiscal técnico; efeitos negativos da remuneração do fiscal técnico

\begin{tabular}{|c|c|c|}
\hline $\begin{array}{l}\text { H3: Quanto maior o nível de } \\
\text { competências privadas, menores os } \\
\text { preços pagos pelo Estado na } \\
\text { aquisição de serviços. }\end{array}$ & $\begin{array}{l}\text { Não suportada } \\
\text { Efeitos negativos da liquidez geral } \\
\text { da empresa na economia }\end{array}$ & $\begin{array}{l}\text { Empresas com melhor liquidez são } \\
\text { menos propensas a oferecer } \\
\text { descontos. }\end{array}$ \\
\hline $\begin{array}{l}\text { H4: A existência de padrões } \\
\text { superiores de competências no setor } \\
\text { privado está associada ao maior } \\
\text { desempenho em contratos de } \\
\text { terceirização de serviços no âmbito } \\
\text { do setor público. }\end{array}$ & $\begin{array}{l}\text { Suportada } \\
\text { Efeitos na dummy de sanções: } \\
\text { Efeitos negativos dos anos de } \\
\text { atuação e do grau de experiência } \\
\text { pública da empresa } \\
\text { Efeitos no tipo de sanções: } \\
\text { Efeitos negativos do grau de } \\
\text { experiência pública da empresa }\end{array}$ & $\begin{array}{l}\text { Empresas mais experientes } \\
\text { possuem maiores conhecimentos } \\
\text { das necessidades específicas da } \\
\text { administração pública, alcançando } \\
\text { níveis de qualidade superiores. }\end{array}$ \\
\hline
\end{tabular}

Nota. Fonte: Resultados da pesquisa.

\section{Conclusões}

Confrontando os resultados obtidos com as hipóteses, verificou-se que, diante de um ambiente caracterizado por baixa competição entre as empresas, adoção de práticas de cartelização e nivelamento para baixo do valor agregado produzido, as capacidades dos agentes públicos possuem efeitos nulos, limitados ou contraditórios no desempenho dos contratos de serviços, particularmente nos indicadores de custo. No caso da formação do fiscal administrativo e do fiscal técnico, notaram-se efeitos de sinal oposto sobre os indicadores de qualidade. Além disso, permanecem dúvidas sobre o motivo de agentes melhor remunerados estarem associados a melhores indicadores de qualidade. É possível supor que, devido aos baixos incentivos, funcionários cuja remuneração não depende da produtividade sejam mais benevolentes na gestão e no monitoramento de contratos. Quanto às competências privadas, apesar dos efeitos positivos da experiência das empresas na qualidade, verificou-se que as capacidades financeiras - em particular a liquidez geral - influenciam negativamente na economia. Trata-se de efeitos provocados por firmas financeiramente mais sólidas que não aceitam oferecer descontos, anulando os efeitos gerados pelas capacidades de negociação dos pregoeiros e reduzindo a economia ex ante. 
Todavia, uma melhor saúde financeira das empresas pode contribuir para reduzir a probabilidade de haver sanções ex post.

A partir das conclusões colocadas, as capacidades financeiras e a experiência acumulada das empresas se destacam entre as contribuições teóricas apresentadas pelo trabalho. À luz dos resultados obtidos, recomenda-se a adoção dos índices financeiros (especialmente da liquidez geral) e da experiência acumulada das empresas para explicar o desempenho dos contratos de serviços no campo das contratações públicas. Quanto às competências públicas, diante de baixos incentivos e de uma estrutura de mercado pouco competitiva, as diversas capacidades de negociação, gestão e monitoramento dos gestores públicos perdem seu potencial de impacto no desempenho dos contratos, contrariando as conclusões de recentes pesquisas sobre os determinantes das economias nas compras públicas. Destaca-se, ainda, a contribuição inédita da presente pesquisa ao desagregar os componentes de competências (capabilities) de servidores públicos brasileiros, de acordo com suas diferentes funções, e verificar a associação dessas variáveis com os indicadores de desempenho dos contratos. Quanto à contribuição prática da pesquisa, espera-se que os resultados obtidos possam ajudar os gestores públicos para tomada de decisões, tanto na contratação quanto na gestão e no monitoramento de contratos.

Entre as principais limitações desta pesquisa, vale destacar o número reduzido de casos observados, restritos a uma única entidade da Administração Pública Federal, cujas características podem afetar os resultados. Na estimação dos efeitos nos custos, o número de observações se reduziu para 77 e, na estimação dos efeitos na qualidade, foram contemplados somente 67 casos, devido especialmente aos missing values associados à economia e aos fiscais. Para novos trabalhos, é recomendável expandir o número de observações, incluindo os contratos de várias instituições, com o intuito de garantir uma maior confiabilidade dos resultados. Além disso, a análise empírica foi conduzida de forma substancialmente descritiva, na medida em que aqui se pretende compreender o objeto de investigação mediante o levantamento sistemático de dados e informações, sem abrir mão da análise (Andrade, 2007). Embora, devido principalmente ao número limitado de casos observados e ao fato de termos investigado os contratos de uma única entidade da administração pública federal, não seja possível defender que exista uma relação de causalidade entre certas variáveis explicativas e os indicadores de desempenho, graças ao trabalho exploratório conduzido podem ser estabelecidas relações de associação e podem ser indicados possíveis caminhos para a continuidade da investigação sobre o tema. Cumpre ressaltar que, no âmbito da área de Administração, no Brasil e no mundo, são raros os trabalhos que utilizam estratégias de identificação, tais como experimentos randomizados controlados, que permitam a observação de causalidade entre variáveis. Essa é uma importante limitação imposta pelo fato de fenômenos organizacionais demandarem a observação de características de difícil codificação ou requererem acesso a informações internas de firmas e governos indisponíveis, seja pela ausência de registro, seja pela pouca propensão de organizações (públicas e privadas) a conferirem acesso a informações e à realização de experimentos controlados. Adicionalmente, lembrando que o estudo possui caráter exploratório, as devidas ressalvas quanto à generalização dos resultados obtidos se aplicam ao presente trabalho.

Com relação às competências públicas, a pesquisa aponta a necessidade de compreender com mais clareza a relação entre formação dos servidores públicos e desempenho. Considera-se necessário entender por que agentes mais qualificados são responsabilizados por contratos com piores índices de desempenho. Analogamente, será importante aprofundar a compreensão dos efeitos da remuneração dos funcionários na qualidade, confrontando contextos caracterizados por estruturas de incentivos diferentes. Quanto às competências privadas, pesquisas futuras poderiam estudar os mecanismos pelos quais as capacidades financeiras dos licitantes afetam as diferentes dimensões do desempenho. Essa avaliação poderá se tornar mais proveitosa, caso se aprofunde sobre como comportamentos de firmas heterogêneas podem influenciar no custo e na qualidade, levando em consideração o ambiente institucional; e em que medida economias conseguidas ex ante podem influenciar nos níveis de qualidade obtidos ex post, dando assim continuidade a uma linha de investigação aberta por estudos recentes. 


\section{Nota}

${ }^{1}$ A pesquisa na qual este artigo está embasado foi apresentada em outro formato e com enfoque diferente em ocasião do EnANPAD 2017.

\section{Material Suplementar}

Os autores optaram por não compartilhar os dados que empregaram na realização dos testes estatísticos e econométricos devido ao fato de pertencerem a uma organização. Por este motivo, preferiram não revelá-los publicamente.

\section{Contribuições}

$1^{\circ}$ e $2^{\circ}$ autor: Os dois autores contribuíram igualmente para produzir o artigo.

\section{Referências}

A Tarde (2007, novembro 24). Acusados da Operação Jaleco Branco começam a prestar depoimentos. Recuperado em 15 de novembro, 2017, de http://atarde.uol.com.br/bahia/salvador/noticias/1244828-acusados-da-operacao-jaleco-brancocomecam-a-prestar-depoimentos

Alchian, A. A., \& Demsetz, H. (1972). Production, information costs, and economic organization. The American Economic Review, 62(5), 777-795.

Andrade, M. M. (2007). Introdução à metodologia do trabalho científico (8a ed.). São Paulo: Atlas.

Andrews, R., Beynon, M. J., \& McDermott, A. M. (2015). Organizational capability in the public sector: A configurational approach. Journal of Public Administration Research and Theory, 26(2), 239258. http://dx.doi.org/10.1093/jopart/muv005

Barney, J. B. (1991). Firm resources and sustained competitive advantage. Journal of Management, 17(1), 99-120. http://dx.doi.org/10.1177/014920639101700108

Beck, T., \& Demirguc-Kunt, A. (2006). Small and medium-size enterprises: Access to finance as a growth constraint. Journal of Banking \& Finance, 30(11), 2931-2943. http://dx.doi.org/10.1016/j.jbankfin.2006.05.009

Bolton, P., \& Dewatripont, M. (2005). Contract theory. Cambridge, MA: MIT Press.

Boyne, G. A. (2002). Public and private management: What's the difference? Journal of Management Studies, 39(1), 97-122. http://dx.doi.org/10.1111/1467-6486.00284

Brown, T. L., \& Potoski, M. (2003). Contract-management capacity in municipal and county governments. Public Administration Review, 63(2), 153-164. http://dx.doi.org/10.1111/15406210.00276

Cabral, S. (2017). Reconciling conflicting policy objectives in public contracting: The enabling role of capabilities. Journal of Management Studies, 54(6), 823-853. http://dx.doi.org/10.1111/joms.12 269. 
Cabral, S., \& Azevedo, P. F. (2008). The modes of provision of prison services in a comparative perspective. Brazilian Administration Review, 5(1), 53-69. Retrieved from http://www.scielo.br/pdf/bar/v5n1/v5n1a05.pdf. 76922008000100005

http://dx.doi.org/10.1590/S1807-

Cabral, S., \& Lazzarini, S. G. (2015). The "Guarding the guardians" problem: An analysis of the organizational performance of an internal affairs division. Journal of Public Administration Research and Theory, 25(3), 797-829. http://dx.doi.org/10.1093/jopart/muu001

Cabral, S., Lazzarini, S. G., \& Azevedo, P. F. (2013). Private entrepreneurs in public services: A longitudinal examination of outsourcing and statization of prisons. Strategic Entrepreneurship Journal, 7(1), 6-25. http://dx.doi.org/10.1002/sej.1149

Cabral, S., \& Saussier, S. (2013). Organizing prisons through public-private partnerships: A crosscountry investigation. Brazilian Administration Review, 10(1), 100-120. Retrieved from http://www.scielo.br/pdf/bar/v10n1/aop1112.pdf. 76922012005000010

Decarolis, F., Giuffrida, L., Iossa, E., Mollisi, V., \& Spagnolo, G. (2017). Buyer quality and procurement outcomes: Explorative evidence from the US. [Working Paper $\mathrm{n}^{\circ}$ 41]. Stockholm Institute of Transition Economics, Stockholm School of Economics. Stockholm, Sweden. Retrieved 11 November, 2017, from http://swopec.hhs.se/hasite/papers/hasite0041.pdf

Dixit, A. (2002). Incentives and organizations in the public sector: An interpretative review. Journal of Human Resources, 37(4), 696-727. http://dx.doi.org/10.2307/3069614

Domberger, S., \& Jensen, P. (1997). Contracting out by the public sector: Theory, evidence, prospects. Oxford Review of Economic Policy, 13(4), 67-78.

Fama, E. F., \& Jensen, M. C. (1983). Separation of ownership and control. Journal of Law and Economics, 26(2), 301-325.

Felin, T., Foss, N. J., Heimeriks, K. H., \& Madsen, T. L. (2012). Microfoundations of routines and capabilities: Individuals, processes, and structure. Journal of Management Studies, 49(8), 13511374. http://dx.doi.org/10.1111/j.1467-6486.2012.01052.x

Girth, A. M. (2012). A closer look at contract accountability: Exploring the determinants of sanctions for unsatisfactory contract performance. Journal of Public Administration Research and Theory, 24(2), 317-348. http://dx.doi.org/10.1093/jopart/mus033

Gujarati, D. N. (2006). Econometria básica (4a ed.). Rio de Janeiro: Elsevier - Campus.

Hair, J. F., Black, W. C., Babin, B. J., Anderson, R. E., \& Tatham, R. L. (2009). Análise multivariada de dados. Porto Alegre: Bookman Editora.

Hart, O., Shleifer, A, \& Vishny, R. (1997). The proper scope of government: Theory and an application to prisons. The Quarterly Journal of Economics, 112(4), 1127-1161. http://dx.doi.org/10.1162/003355300555448

Iudícibus, S. D. (1994). Análise de balanços (6a ed.). São Paulo: Atlas.

Kim, S. M., \& Mahoney, J. T. (2006). Mutual commitment to support exchange: Relation specific IT system as a substitute for managerial hierarchy. Strategic Management Journal, 27(5), 401-423. http://dx.doi.org/10.1002/smj.527

Kivleniece, I., \& Quelin, B. V. (2012). Creating and capturing value in public-private ties: A private actor's perspective. Academy of Management Review, 37(2), 272-299. http://dx.doi.org/10.5465/amr.2011.0004 
Liu, X. (2016). Applied ordinal logistic regression using Stata: From single-level to multilevel modeling. Thousand Oaks: Sage Publications.

Mahoney, J. T., McGahan, A. M., \& Pitelis, C. N. (2009). The interdependence of private and public interests. Organization Science, 20(6), 1034-1052. http://dx.doi.org/10.1287/orsc.1090.0472

Ménard, C. (2012). Hybrid modes of organization. alliances, joint ventures, networks, and other 'strange' animals. In R. Gibbons \& J. Roberts (Orgs.), The handbook of organizational economics (pp. 1066-1108). Princeton: Princeton University Press

Miller, G. (2000). Above politics: Credible commitment and efficiency in the design of public agencies. Journal of Public Administration Research and Theory, 10(2), 289-327.

Ministério do Planejamento. Secretária de Logística e Tecnologia da Informação. (2015). Informações gerenciais de contratações e compras públicas. Recuperado em 19 de fevereiro, 2015, de http://www.comprasgovernamentais.gov.br/arquivos/estatisticas/01-apresentacao-siasgdadosgerais_2014.pdf

Pereira, L. C. B. (1997). A reforma do Estado dos anos 90: Lógica e mecanismos de controle. Brasília: MARE, Ministério da Administração Federal e Reforma do Estado.

Previdência Social. (2017, maio 11). Tabela de contribuição - Histórico. Brasília. Recuperado em 4 de julho, 2017, de https://www.inss.gov.br/servicos-do-inss/calculo-da-guia-da-previdencia-socialgps/tabela-de-contribuicao-mensal/tabela-de-contribuicao-historico/

Rangan, S., Samii, R., \& Van Wassenhove, L. N. (2006). Constructive partnerships: When alliances between private firms and public actors can enable creative strategies. Academy of Management Review, 31(3), 738-775. http://dx.doi.org/10.2307/20159239

Reis, P. R. (2016). Desempenho nos contratos de compras públicas: Evidências empíricas das mudanças institucionais no Brasil (Tese de doutorado). Universidade Federal da Bahia, Salvador, BA, Brasil. Recuperado de https://repositorio.ufba.br/ri/bitstream/ri/19468/1/REIS,\%20Paulo\%20Ricardo\%20da\%20Costa. pdf

Reis, P. R., \& Cabral, S. (2015). Public procurement strategy: The impacts of a preference programme for small and micro businesses. Public Money \& Management, 35(2), 103-110. http://dx.doi.org/10.1080/09540962.2015.1007704

Reis, P. R., \& Cabral, S. (2016, setembro). Para além dos preços contratados: Uma análise da celeridade nas entregas de compras públicas eletrônicas. Anais do Encontro Nacional da Associação Nacional de Pós-Graduação e Pesquisa em Administração, Costa de Sauípe, Mata de São João, BA, Brasil, 40. Recuperado em 6 de outubro, 2016, de http://www.anpad.org.br/ anpad/abrir_pdf.php?e=MjA5MzI=

Spagnolo, G. (2012). Reputation, competition, and entry in procurement. International Journal of Industrial Organization, 30(3), 291-296. http://dx.doi.org/10.1016/j.ijindorg.2012.01.001

Tadelis, S. (2012). Public procurement design: Lessons from the private sector. International Journal of Industrial Organization, 30(3), 297-302. http://dx.doi.org/10.1016/j.ijindorg.2012.02.002

Teece, D. J., Pisano G., \& Shuen, A. (1997). Dynamic capabilities and strategic management. Strategic Management Journal, 18(7), 509-533. http://dx.doi.org/10.1002/(SICI)10970266(199708)18:7<509::AID-SMJ882>3.0.CO;2-Z

Tribuna da Bahia. (2009, março 14). Bloqueados $R \$ 40$ milhões de envolvidos na Operação Jaleco $\begin{array}{lllll}\text { Branco. } & \text { Recuperado abril, } & 2017, & \text { de }\end{array}$ 
http://www.tribunadabahia.com.br/2009/03/14/bloqueados-r\$-40-milhoes-de-envolvidos-naoperacao-jaleco-branco

Universidade Federal da Bahia. (2015). Relatório de gestão - Exercício 2014. Recuperado em 20 de fevereiro, 2017, de https://proplan.ufba.br/documentacao-legislacao/relatorios-gestao

Universidade Federal da Bahia. (2016). Relatório de gestão - Exercício 2015. Recuperado em 17 fevereiro, 2017, de https://proplan.ufba.br/documentacao-legislacao/relatorios-gestao

White, H. (1980). A heteroskedasticity-consistent covariance matrix estimator and a direct test for heteroskedasticity. Econometrica: Journal of the Econometric Society, 48(4), 817-838. http://dx.doi.org/10.2307/1912934

Williamson, O. E. (1996). The mechanisms of governance. Oxford: Oxford University Press.

Williamson, O. E. (1999). Public and private bureaucracies: A transaction cost economics perspective. Journal of Law, Economics and Organization, 15(1), 306-342.

Williamson, O. E. (2005). Por que direito, economia e organizações? In D. Zylbersztajn \& R. Sztajn (Orgs.), Direito e economia: Análise econômica do direito e das organizações (pp. 16-59). Rio de Janeiro: Elsevier.

Winter, S. G. (2003). Understanding dynamic capabilities. Strategic Management Journal, 24(10), 991995. http://dx.doi.org/10.1002/smj.318

Wooldridge, J. M. (2002). Econometric analysis of cross-section and panel data. Cambridge: MIT Press.

Wooldridge, J. M. (2013). Introductory econometrics: A modern approach (5th ed.). Stamford: Cengage Learning.

Zollo, M., \& Winter, S. G. (2002). Deliberate learning and the evolution of dynamic capabilities. Organization Science, 13(3), 339-351. http://dx.doi.org/10.1287/orsc.13.3.339.2780

\section{Dados dos Autores}

Francesco Bonelli

Av. Reitor Miguel Calmon, s/n, Vale do Canela, 40110-903, Salvador, BA, Brasil. E-mail: francescobonelli@gmail.com. http://orcid.org/0000-0001-8628-9068

Sandro Cabral

Av. Reitor Miguel Calmon, s/n, Vale do Canela, 40110-903, Salvador, BA, Brasil. E-mail: sandro.cabral@uol.com.br. http://orcid.org/0000-0002-8663-2441 